Copper(I) complexes of 8-(diphenylphosphanyl-oxy)-quinoline : Photophysics, structures and reactivity

\title{
Wallesch, Manuela
}

2017-12

Wallesch , M , Nieger , M , Volz , D \& Bräse , S 2017 , ' Copper(I) complexes of 8-(diphenylphosphanyl-oxy)-quinoline : Photophysics, structures and reactivity ', Inorganic Chemistry Communications, vol. 86 , pp. 232-240 . https://doi.org/10.1016/j.inoche.2017.10.012

http://hdl.handle.net/10138/309255

https://doi.org/10.1016/j.inoche.2017.10.012

cc_by_nc_nd

acceptedVersion

Downloaded from Helda, University of Helsinki institutional repository.

This is an electronic reprint of the original article.

This reprint may differ from the original in pagination and typographic detail.

Please cite the original version. 


\title{
Copper(I) complexes of 8-(diphenylphosphanyl-oxy)- quinoline: Photophysics, Structures and Reactivity
}

\author{
Manuela Wallesch,, ${ }^{1,2}$ Martin Nieger, 3 Daniel Volz ${ }^{4^{*}}$ and Stefan Bräse ${ }^{1^{*}}$ \\ IInstitute of Organic Chemistry, Karlsruhe Institute of Technology, Kaiserstr. 12, 76131 Karlsruhe, Germany; ${ }^{2}$ Institute of Toxicol- \\ ogy and Genetics, Karlsruhe Institute of Technology, Kaiserstr. 12, 76131 Karlsruhe, Germany; 3 Laboratory of Inorganic Chemistry, \\ University of Helsinki, P.O. Box 55, FIN-ooo14, Finland; ${ }^{4}$ cynora GmbH, Werner-von-Siemensstraße 2-6, building 5110, 76646 \\ Bruchsal, Germany.
}

Supporting Information Placeholder

\begin{abstract}
Copper(I) complexes are studied for various potential applications due to their luminescence properties. However, issues have been identified regarding the stability of heteroleptic compounds. As a novel strategy, we propose to modify existing copper(I) complexes by introduction of molecular bridges between the different ligands. We report the synthesis and chemical properties of the complexes of 8-(diphenylphosphanyl-oxy)quinoline (POQ), a combination of a phosphine and a N-heterocycle with $\mathrm{CuX}(\mathrm{X}=\mathrm{Cl}, \mathrm{Br}$, I and $\mathrm{SCN})$. The photophysical properties of the materials were studied. However, all four compounds were found to be labile in solution upon contact with trace amounts of water. Two POQ complexes and the decomposition products were identified as tetraphenyldiphosphoxane complexes with single crystal X-ray diffraction. We propose a design rule to prevent this behavior in future development steps.
\end{abstract}

\section{INTRODUCTION}

Luminescent copper(I) complexes are studied for various potential applications, e.g., as sustainable emitters in organic light-emitting diodes (OLEDs) ${ }^{1,2}$, light-emitting electrochemical cells, and photocatalysts ${ }^{3,4} .5$ Recently, the efficiency-gap between state-of-the-art phosphorescent iridium emitters and copper-emitters, which often emit via thermally activated delayed fluorescence (TADF) has been closed, ${ }^{6}$ which puts copper emitters on par with the most efficient molecules known for the transformation of UV-light or electrical energy into visible light. However, the search for better materials is ongoing: Realizing deepblue or red emitters with copper is - with some exceptions $^{7-10}$ - still an issue and the general long-term stability has to be enhanced to reach the durability that is needed for commercial products. This requires a deep understanding of the chemical properties of copper emitters. ${ }^{11,12}$

Symmetric, dinuclear heteroleptic complexes of the type NPCuXXCuNP (see Scheme 1, left structure) were first structurally investigated by the group of White and co-workers. ${ }^{13-19}$ Recently, Tsuge et al. reported that these materials are also interesting emitting materials and that their color can be tuned by varying either the halides (X, Scheme 1) or the N-heterocycles. ${ }^{20}$ From quantumchemical calculations, it is known that the emissive transition for similar compounds is a result of a metal- halide-to-ligand charge transfer $((\mathrm{M}+\mathrm{X}) \mathrm{LCT})$ between the dinuclear copper-halide subunit and the N-heterocycles. ${ }^{9}$

Scheme 1: Modification of heteroleptic copper(I) complexes by introduction of molecular bridges. The color may be tuned by varying either the halides $\mathrm{X}$ or the $\mathrm{N}$ heterocycles. ${ }^{20}$
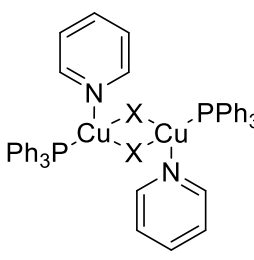

heteroleptic

$\mathrm{X}=$ halide

pseudohalide

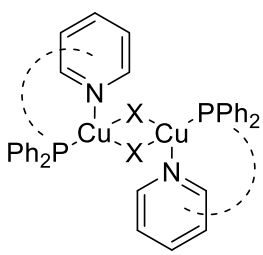

bridged
The influence of the phosphine on the emission properties is negligible..$^{9,21,22}$ Potential stability problems with such heteroleptic compounds, which are the result of a cleavage of the $\mathrm{N}-\mathrm{Cu}$ bond, were reported previously by our group. ${ }^{23}$ The instability of these compounds may hamper their durability in OLED devices. We propose a new strategy to overcome these issues: The introduction of inert bridges between the phosphine and $\mathrm{N}$ heterocyclic ligands to stabilize those dinuclear structures with kinetically favored five- or six-membered metallacycles. ${ }^{6}$ A similar strategy was introduced by 
Yersin and Wesemann, where five-membered rings were yielded by direct fusion of amines with phosphines.7 Potential bridges are short alkyl-chains or ether- or thioether-bridges. In a first attempt, we chose a single oxygen as a bridge between diphenylphosphine and a $\mathrm{N}$ heterocycle. Because of the current lack of efficient red copper emitters, we used the quinoline-moiety to test this hypothesis due to its narrow HOMO-LUMO difference, high chemical stability and encouraging previous results with similar structures..$^{10,20,24}$

\section{EXPERIMENTAL SECTION}

Experimental procedures for the spectroscopic methods as well as synthetic details and conditions used in the preparation of single crystal samples are given in the supporting information.

Fusing phosphine and $\mathrm{N}$-donor moieties in one chelating ligand was achieved by combination of diphenylphosphine as P-donor, quinoline as $\mathrm{N}$-donor, and oxygen as the bridging unit, which yields ligand 1 (POQ, (diphenylphosphanyl-oxy)-quinoline, see Figure 1). The synthesis of the ligand is straight-forward and could easily be performed in large batches by reacting equimolar amounts of chlorodiphenyl phosphine and 8hydroxyquinoline in the prescence of dry triethylamine. Ligand $\mathbf{1}$ could be purified by multiple recrystallization to get a pure product. The synthesis of the copper(I) complexes was performed in dry dichloromethane by mixing of stoichiometric amounts of copper precursors with 1 and precipitation of the product. For the synthesis of copper(I) complexes, we found that using noncrystallized ligand 1, which can be obtained by filtering the reaction mixture of celite and removal of the solvent, is sufficient.

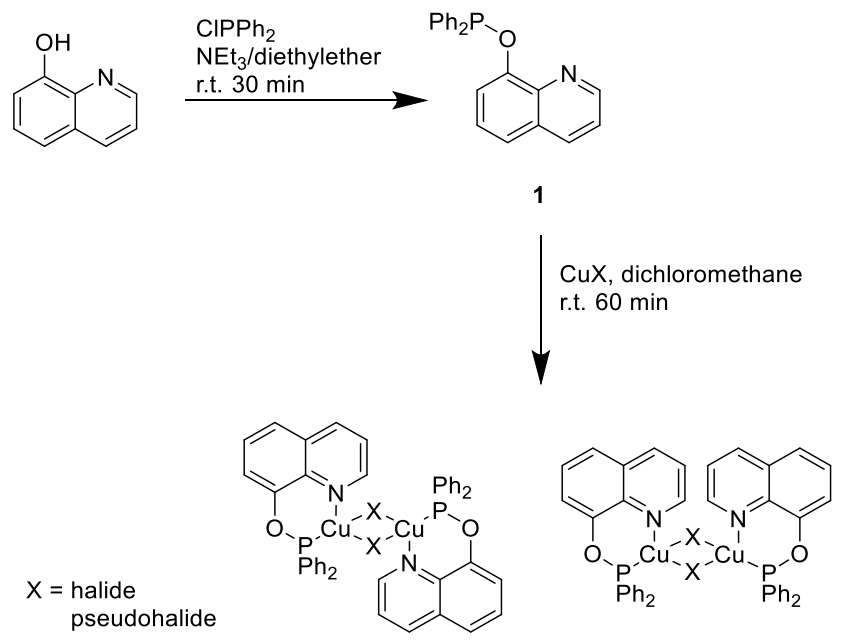

Figure 1: Synthesis of ligand 1 (POQ) and complexation with copper precursors yields dinuclear complexes.
Reaction of POQ with precursor salts $\mathrm{CuX}(\mathrm{X}=\mathrm{Cl}, \mathrm{Br}, \mathrm{I}$, $\mathrm{SCN}$ ) was performed as previously described in the literature. ${ }^{25}$ The products were obtained by diffusion of cyclohexane into the clear, yellow reaction mixtures or by precipitation from the reaction mixture with hexane (bulk samples) to yield the complexes $\mathbf{1}-\mathbf{C l}, \mathbf{1}-\mathbf{B r}, \mathbf{1}-\mathbf{I}$ and $\mathbf{1}-\mathbf{S C N}$.

\section{RESULTS \\ Photophysical properties of 1-Cl, 1-Br, 1-I and 1- SCN}

The photophysical properties of $\mathbf{1}-\mathbf{C l}, \mathbf{1}-\mathbf{B r}, \mathbf{1}-\mathbf{I}$ and $\mathbf{1 -}$ SCN were studied in solid state under nitrogen to prevent triplet quenching from oxygen. We found that only $\mathbf{1}-\mathbf{B r}$ is luminescent at room temperature. Upon cooling to $77 \mathrm{~K}$ (liquid nitrogen bath), all samples showed weak or very weak luminescence. However, only $\mathbf{1}-\mathbf{C l}$ and $\mathbf{1}-\mathbf{B r}$ gave satisfactory PL spectra (Figure 2). At room temperature, the photoluminescence quantum yield of $\mathbf{1}-\mathbf{C l}$ was below $1 \%$, while $\mathbf{1 - B r}$ yielded a mediocre PLQY of $10 \pm 1 \%$.

As can be seen in Figure 2, all emission spectra are broad and ill-structured, as it is expected for $(\mathrm{M}+\mathrm{X}) \mathrm{LCT}$ emission. The emission of $\mathbf{1}-\mathbf{B r}$ is centered in the orangeto-red region around $590 \mathrm{~nm}$ at room temperature and around $610 \mathrm{~nm}$ at $77 \mathrm{~K}$, while $\mathbf{1}-\mathrm{Cl}$ emits around $625 \mathrm{~nm}$ at 77 K. All spectra have a broadness of $0.4 \pm 0.1 \mathrm{eV}$. Similar to related compounds introduced by Tsuge and coworkers, ${ }^{9,10,26}$ the large $\pi$-system of the quinoline moiety leads to a stabilization of the LUMO and consequently to a profound red-shift, which can be further enhanced by destabilizing the HOMO, by moving from bromide to chloride. Also, from the fact that the color is profoundly red-shifted upon cooling (1-Br) and that the PLQY seems to be increased at lower temperatures, one could speculate that the material is a TADF-emitter, as it was found for other dinuclear $\mathrm{Cu}(\mathrm{I})$ complexes. ${ }^{7}$ To confirm this assumption, a deeper spectroscopic analysis is necessary.

Even though the ligand-fusion works in principle and yielded orange-to-red emitting compounds, there remain open questions: First, the PLQY needs to be increased further. The fact that the PLQY is low, but is increased upon cooling to low temperatures for $\mathbf{1}-\mathbf{C l}, \mathbf{1}-\mathbf{B r}, \mathbf{1}-\mathbf{I}$, and $\mathbf{1 -}$ $\mathbf{S C N}$, is a hint that there are strong, temperaturedependent quenching processes present. Second, it is noticeable that the bromide-derivative has the highest PLQY. In most cases, the PLQY either increases or decreases when moving from $\mathrm{Cl}$ to $\mathrm{Br}$ to $\mathrm{I} .9,24$ The different behavior in this case might be due to differences in the molecular structure of the samples. This will be further elucidated in the section, where XRD results are discussed. 


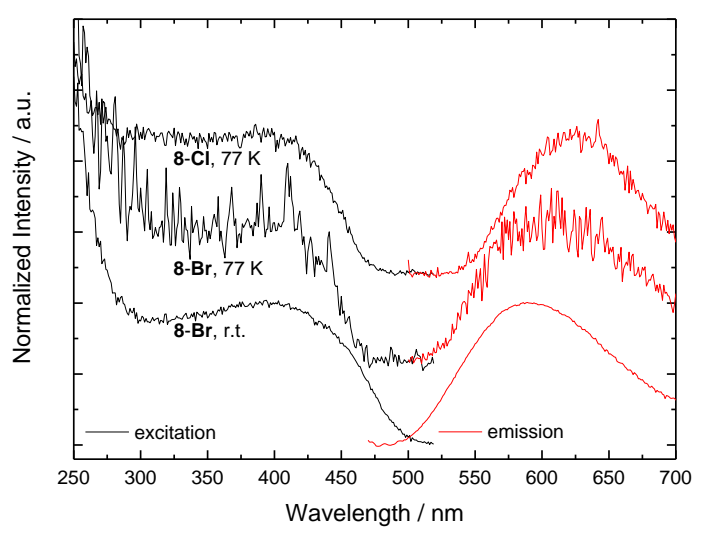

Figure 2: Excitation $\left(\lambda_{\mathrm{Em} .}=600 / 625 \mathrm{~nm}\right)$ and emission $\left(\lambda_{\text {Ex. }}=370 / 390 \mathrm{~nm}\right)$ spectra of powder samples of complexes $\mathbf{1}-\mathbf{B r}$ at r.t. and $77 \mathrm{~K} /$ complex $\mathbf{1}-\mathbf{C l}$ at $77 \mathrm{~K}$.

\section{Coordination chemistry of POQ}

The molecular structure of $\mathbf{1}-\mathbf{B r}$ and $\mathbf{1 - I}$ could be determined with single crystal X-ray diffraction (Figures 3 and 4). As expected, both compounds consist of a dinuclear $\mathrm{Cu}_{2} \mathrm{X}_{2}$-unit with two molecules of POQ chelating the copper atoms. However, there are fundamental differences in the two structures: $\mathbf{1}-\mathbf{B r}$ is a centro-symmetric molecule with a planar $\mathrm{Cu}_{2} \mathrm{Br}_{2}$-unit, which is similar to the related compound published by Tsuge et al. ${ }^{20}$ On the other hand, $\mathbf{1 - I}$ has mirror symmetry and features a bent, butterfly-shaped $\mathrm{Cu}_{2} \mathrm{I}_{2}$-unit, much like the NHetPHOS-compounds developed by our group..$^{21,27,28}$

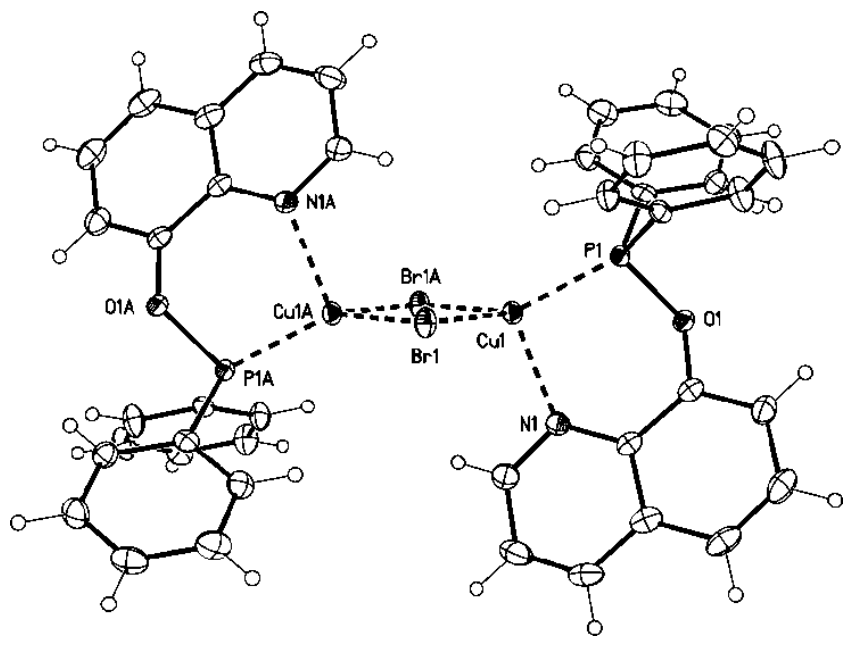

Figure 3: Molecular structure of complex 1-Br. Displacement parameter drawn at the $50 \%$ probability level. The molecule possesses crystallographic $\mathrm{C}_{\mathrm{i}}$-symmetry.

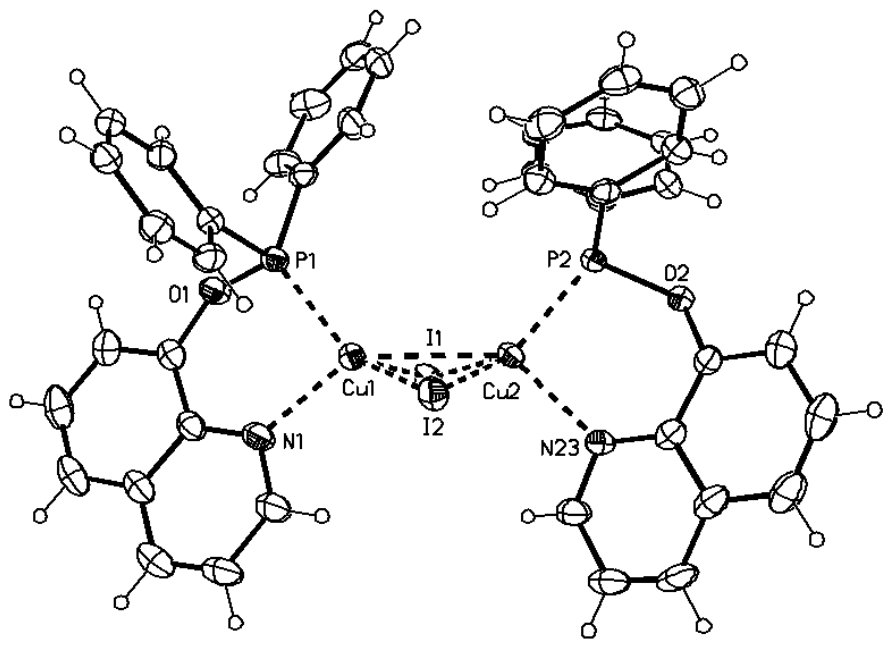

Figure 4: Molecular structure of complex 1-I. Displacement parameter drawn at the 50\% probability level.

Table 2: Selected bond lengths (in $\AA$ ) for $\mathbf{1}-\mathbf{B r}$ and 1-I.

\begin{tabular}{lll}
\hline & \multicolumn{1}{l}{$\mathbf{1 - B r}$} & $\mathbf{1}-\mathbf{I}$ \\
\cline { 2 - 3 } $\mathrm{Cu}-\mathrm{X}$ & $2.4348(4)$ & $2.6097(5)$ \\
& $2.4888(6)$ & $2.6600(6)$ \\
& & $2.5699(5)$ \\
& & $2.6462(6)$ \\
$\mathrm{Cu}-\mathrm{N}$ & $2.132(2)$ & $2.135(3)$ \\
$\mathrm{Cu}-\mathrm{P}$ & & $2.169(3)$ \\
& $2.1532(7)$ & $2.1789(9)$ \\
$\mathrm{P}-\mathrm{O}$ & & $2.1854(9)$ \\
& & $1.652(2)$ \\
$\mathrm{C}$ & & $1.650(2)$ \\
& & $1.380(4)$ \\
& & $1.387(4)$ \\
\hline
\end{tabular}

Table 3: Bond distances (in $\AA$ ) in various representative copper(I) complexes from the literature.

\begin{tabular}{|c|c|c|}
\hline $\begin{array}{l}\text { bond, } \\
\text { compound }\end{array}$ & source $^{*}$ & bond distances \\
\hline \multicolumn{3}{|l|}{$\mathrm{Cu}-\mathrm{I}$} \\
\hline copper(I)iodide & 29 & 2.6414 \\
\hline$[$ CuI(pyridine $)]_{\mathrm{n}}$ & 30 & $2.641(1)-2.689(1)$ \\
\hline$\left[\mathrm{CuI}\left(\mathrm{PPh}_{3}\right)\right]_{4}$ & 31 & $2.653(3)-2.732(3)$ \\
\hline$\left[\mathrm{CuI}(\right.$ pyridine $\left.)\left(\mathrm{PPh}_{3}\right)_{2}\right]$ & 32 & $2.636(1)$ \\
\hline$[\mathrm{CuI} \text { (quinoline) }]_{2}$ & 33 & $2.657(3)-2.668(2)$ \\
\hline$[\mathrm{CuI} \text { (quinoline) }]_{4}$ & 32 & $2.680(6)-3 \cdot 394(12)$ \\
\hline \multicolumn{3}{|l|}{$\mathrm{Cu}-\mathrm{Br}$} \\
\hline copper(I)bromide & 29 & 2.5201 \\
\hline
\end{tabular}




\begin{tabular}{|c|c|c|}
\hline$[\mathrm{CuBr}(\text { pyridine })]_{\mathrm{n}}$ & 30 & $2.450(5)-2.557(3)$ \\
\hline$\left[\mathrm{CuBr}\left(\mathrm{PPh}_{3}\right)\right]_{4}$ & 34 & $2.491(2)-2.617(2)$ \\
\hline$\left[\mathrm{CuBr}(\right.$ pyridine $\left.)\left(\mathrm{PPh}_{3}\right)_{2}\right]$ & 32 & $2.459(2)$ \\
\hline$[\mathrm{CuBr} \text { (quinoline) }]_{2}$ & 35 & $2.493(3)-2.680(3)$ \\
\hline$[\mathrm{CuBr} \text { (quinoline) }]_{4}$ & 36 & $2.381(4)-2.851(2)$ \\
\hline \multicolumn{3}{|l|}{$\mathrm{Cu}-\mathrm{Cl}$} \\
\hline copper(I)chloride & 29 & 2.3820 \\
\hline$[\mathrm{CuCl}(\text { pyridine })]_{\mathrm{n}}$ & 30 & $2.338(4)-2.530(2)$ \\
\hline$\left[\mathrm{CuCl}\left(\mathrm{PPh}_{3}\right)\right]_{4}$ & 37 & $2.363(2)-2.505(2)$ \\
\hline$[\mathrm{CuCl}$ (pyridine $\left.)\left(\mathrm{PPh}_{3}\right)_{2}\right]$ & 32 & $2.318(2)$ \\
\hline$[\mathrm{CuCl} \text { (quinoline) }]_{2}$ & 35 & $2.357(7)-2.675(6)$ \\
\hline$[\mathrm{CuCl} \text { (quinoline) }]_{4}$ & 36 & $2.311(5)-2.510(5)$ \\
\hline \multicolumn{3}{|l|}{$\mathrm{Cu}-\mathrm{N}$} \\
\hline$[\text { CuI(pyridine) }]_{\mathrm{n}}$ & 30 & $2.038(6)$ \\
\hline$[\mathrm{CuBr}(\text { pyridine })]_{\mathrm{n}}$ & 30 & $2.00(1)$ \\
\hline$[\mathrm{CuCl}(\text { pyridine })]_{\mathrm{n}}$ & 30 & $1.993(8)$ \\
\hline$[\mathrm{CuSCN}(\text { pyridine })]_{\mathrm{n}}$ & 38 & $2.054(5)-2.103(2)$ \\
\hline$\left[\mathrm{CuI}(\right.$ pyridine $\left.)\left(\mathrm{PPh}_{3}\right)_{2}\right]$ & 32 & $2.131(5)$ \\
\hline$\left[\mathrm{CuBr}(\right.$ pyridine $\left.)\left(\mathrm{PPh}_{3}\right)_{2}\right]$ & 32 & $2.145(9)$ \\
\hline$\left[\mathrm{CuCl}(\right.$ pyridine $\left.)\left(\mathrm{PPh}_{3}\right)_{2}\right]$ & 32 & $2.130(2)$ \\
\hline$\left[\mathrm{CuSCN}(\right.$ pyridine $\left.)\left(\mathrm{PPh}_{3}\right)_{2}\right]$ & 39 & $2.070(1)-2.091(2)$ \\
\hline$[\text { CuI(quinoline) }]_{2}$ & 33 & $2.076(5)-2.104(5)$ \\
\hline$[\mathrm{CuBr} \text { (quinoline) }]_{2}$ & 35 & $2.01(1)-2.07(2)$ \\
\hline$[\mathrm{CuCl} \text { (quinoline) }]_{2}$ & 35 & $2.00(2)-2.08(2)$ \\
\hline \multicolumn{3}{|l|}{$\mathrm{Cu}-\mathrm{P}$} \\
\hline$\left[\mathrm{CuI}\left(\mathrm{PPh}_{3}\right)\right]_{4}$ & 31 & $2.251(6)-2.258(7)$ \\
\hline$\left[\mathrm{CuBr}\left(\mathrm{PPh}_{3}\right)\right]_{4}$ & 34 & $2.206(3)-2.209(3)$ \\
\hline$\left[\mathrm{CuCl}\left(\mathrm{PPh}_{3}\right)\right]_{4}$ & 37 & $2.192(2)-2.193(2)$ \\
\hline$\left[\mathrm{CuI}(\right.$ pyridine $\left.)\left(\mathrm{PPh}_{3}\right)_{2}\right]$ & 32 & $2.283(2)-2.292(2)$ \\
\hline$\left[\mathrm{CuBr}(\right.$ pyridine $\left.)\left(\mathrm{PPh}_{3}\right)_{2}\right]$ & 32 & $2.277(3)-2.286(4)$ \\
\hline$\left[\mathrm{CuCl}(\right.$ pyridine $\left.)\left(\mathrm{PPh}_{3}\right)_{2}\right]$ & 32 & $2.256(1)-2.272(1)$ \\
\hline$\left[\mathrm{CuSCN}(\right.$ pyridine $\left.)\left(\mathrm{PPh}_{3}\right)_{2}\right]$ & 39 & $2.1974(5)$ \\
\hline
\end{tabular}

*also refer to Table $\mathrm{S}_{1}$ in the supporting information

A similar behavior was found for other dinuclear compounds by Yersin and Wesemann, where a bridging N,P ligand yielded a centro-symmetric compound, similar to $\mathbf{1 - B r}$ with $\mathrm{X}=\mathrm{Cl}$, and a mirror-symmetric compound similar to 1-I with $\mathrm{X}=\mathrm{Br}$ and I.7 This could be a reason for the abnormal trends found in the photophysical experiments when moving from $\mathrm{Cl}$ to $\mathrm{Br}$ to $\mathrm{I}$.

Selected bond lengths for $\mathbf{1}-\mathbf{B r}$ and $\mathbf{1 - I}$ are given in Table 2. Comparison with reference compounds (see Table 3, Table S2 in the supporting information) shows that the $\mathrm{Cu}$-halide and $\mathrm{Cu}-\mathrm{N}$ bond lengths are similar to those in other copper(I) complexes: The $\mathrm{Cu}$-halide bonds are in the expected range, but will not be discussed further due to the rather larger variance (see Table 3 ). The $\mathrm{Cu}-\mathrm{N}$ bonds are also in the expected range: While there are no known reference compounds with $\mathrm{Cu}(\mathrm{I})$ - phosphine-quinoline-coordination, it can be seen that the $\mathrm{Cu}-\mathrm{N}$ bond gets longer when moving from $\mathrm{Cu}(\mathrm{I})$-pyridine to $\mathrm{Cu}(\mathrm{I})$-pyridine-phosphine and that the $\mathrm{Cu}-\mathrm{N}$ bond for $\mathrm{Cu}(\mathrm{I})$-quinoline $(2.13 \AA)$ is in a similar range as for $\mathrm{Cu}(\mathrm{I})$ pyridine-phosphine.

However, the $\mathrm{Cu}-\mathrm{P}$ and the $\mathrm{P}-\mathrm{O}$ bond lenghts deviate from the expected values: It is evident that the $\mathrm{Cu}-\mathrm{P}$ bonds for both compounds are roughly 0.04-0.14 shorter than expected. While in most known cases, this bond is in the order of 2.19-2.29 $\AA$, they are only $2.15 / 2.18$ $\AA$ for 1-Br/1-I, respectively. More anomalies can be found in the ligand backbone of the POQ-unit. So far, only two other publications with POQ are available, studying the coordination chemistry with $\mathrm{Ni}(\mathrm{II})^{40}$ as well as $\mathrm{Fe}(\mathrm{II})$ and $\mathrm{Ru}(\mathrm{II}) .{ }^{41}$ Nevertheless, the P-O bond seems to be slightly longer than expected (approx. 0.02-0.04 $\AA$ ), while the $\mathrm{C}_{\text {quin }}-\mathrm{O}$ bond is again close to the expected value.

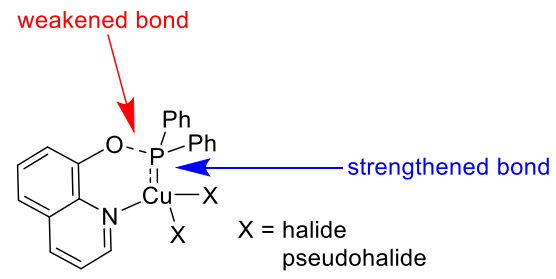

Figure 5: We hypothesize that the $\mathrm{P}-\mathrm{O}$ bond is weakened upon coordination of POQ to copper(I), whereas the $\mathrm{Cu}$ $\mathrm{P}$ bond is stronger than in other complexes.

If the difference in bond lengths is considered to be a hint for strengthened (shortening) or weakening (elongation) of the respective bond, coordination of POQ to copper halides seems to weaken the bond between the $\mathrm{PPh}_{2}$ unit and the quinolate unit, while the bond between $\mathrm{PPh}_{2}$ and $\mathrm{Cu}(\mathrm{I})$ is stronger than usual. It is unlikely that the bond length anomalies are caused by steric hindrance and the presence of a chelating ligand. Usually, such effects are more likely to cause distorted bond angles, as it was found for other dinuclear copper(I) complexes. ${ }^{21}$ The presence of elongated or shortened bonds has two important consequences: i) upon photoexcitation, such bonds could be cleaved or open up non-radiative relaxation pathways and ii) the elongated bond is more likely to be cleaved.

In the next section, we will further discuss the latter aspect.

\section{Degradation of POQ-copper(I) complexes: POP complexes}

Various crystallization experiments with a copper precursor ( $\mathrm{CuCl}, \mathrm{CuBr}, \mathrm{CuI}$, and $\mathrm{CuSCN}$ ) and POQ by diffusion of diethyl ether into acetonitrile solutions were performed. For POP-Br-2, triphenylphosphine was added. We were able to isolate single crystal samples of three compounds (Figure 6, Figure 7, and Figure 8). 


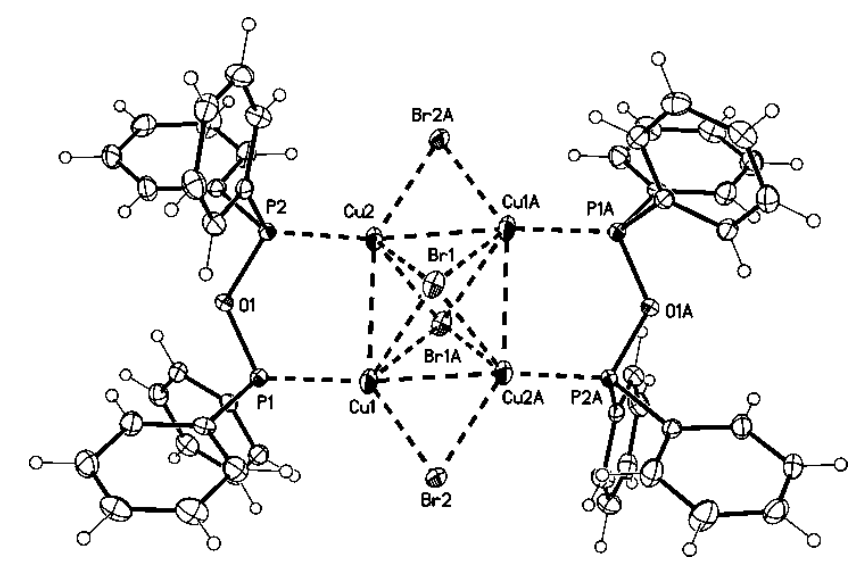

Figure 6: Molecular structure of complex POP-Br-1. Displacement parameter drawn at the $50 \%$ probability level. The molecule possesses crystallographic $\mathrm{C}_{\mathrm{i}}{ }^{-}$ symmetry.

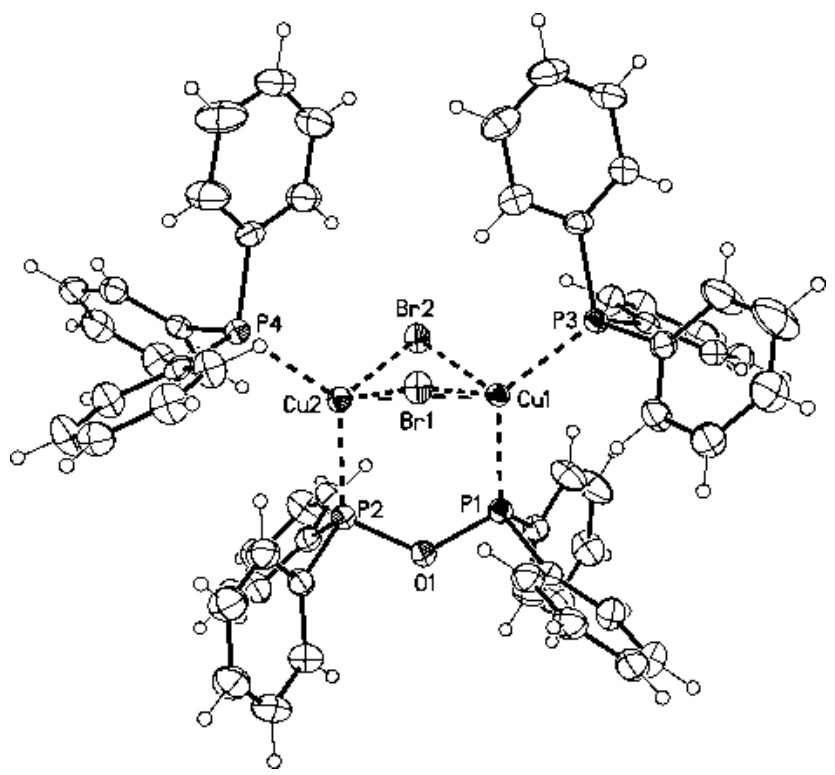

Figure 7: Molecular structure of complex POP-Br-2. Displacement parameter drawn at the $50 \%$ probability level. Only the major isomer (ca. 96\%) is depicted.

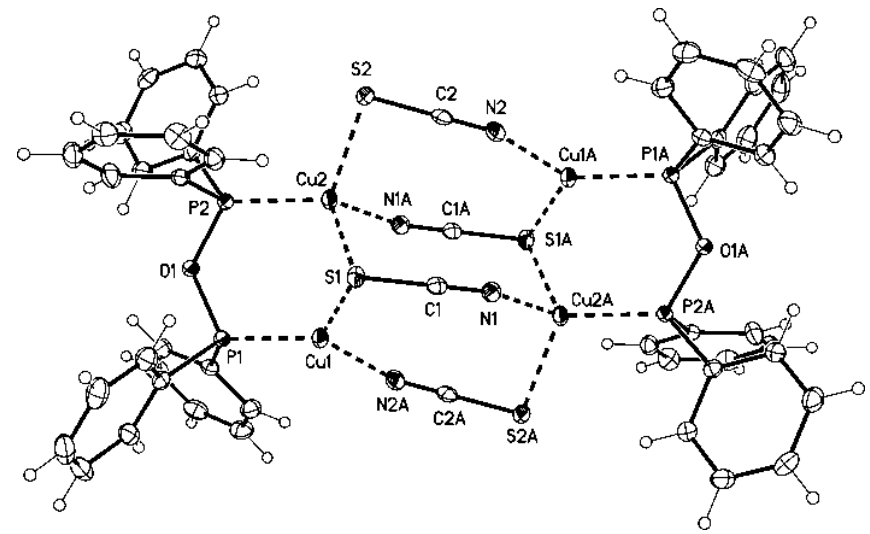

Figure 8: Molecular structure of complex POP-SCN. Displacement parameter drawn at the $50 \%$ probability level. The molecule possesses crystallographic $\mathrm{C}^{-}$ symmetry.
All three isolated compounds did not contain the initial ligand POQ. Instead, we found a bridging bisphosphine ligand $\left(\mathrm{PPh}_{2}\right) \mathrm{O}\left(\mathrm{PPh}_{2}\right) /(\mathrm{POP})$. Tetraphenyldiphosphoxane (POP) is the tautomeric form of tetraphenyldiphosphine monoxide (PPO), which can be synthesized by hydrolysis of chlorodiphenylphosphine. Without the presence of coordinating metal ions, PPO is the dominating tautomer, while POP can be stabilized in the presence of transition metal ions. Early results for POP complexes were published in the 1970 s with $\mathrm{Cr}$, Mo, and $\mathrm{W}$ as metal centers. ${ }^{42-44}$ Depending on the metal fragments, POP may coordinate in a bridging or chelating way, the latter yielding four-membered rings. Naktode and co-workers recently reported the first copper(I) complexes of the POP ligand, ${ }^{45}$ which was obtained by the hydrolysis of N,N-bis-(diphenylphosphino)-aniline with copper halides in $\mathrm{CH}_{2} \mathrm{Cl}_{2}$ :water mixtures. Interestingly, this procedure yielded not only POP complexes, but also multinuclear, heteroleptic complexes with POP as well as its isomer PPO, when additional triphenyl phosphine was present.

The degradation only occurred when protic solvents such as acetonitrile or alcohols were present. From analyses of aged solutions of complex 1-I in dichloromethane, non-dried acetonitrile as well as acetonitrile-water (1:1) with gas chromatography, we were able to rule out a transfer of oxygen from the oxyquinoline moiety: We could verify the formation of PPO and 8-hydroxyquinoline, while neither quinoline, nor diquinolinylether or other coupling products were found. Trace amounts of water, which may be present in acetonitrile, destabilize the complexes by protonation of the quinoline-moieties and serve as a source for the oxygen in the POP ligand. Furthermore, the oxidation of the coordinated ligand by $\mathrm{O}_{2}$ does not seem to be of relevance for our system, given that we were able to isolate to compounds $\mathbf{1}-\mathbf{C l}, \mathbf{1}-\mathbf{B r}, \mathbf{1}-\mathbf{I}$ and $\mathbf{1}-\mathbf{S C N}$ as powder samples at ambient conditions.

Scheme 1: Chemistry of the tetraphenyldiphosphoxane (POP) ligand. ${ }^{2}$
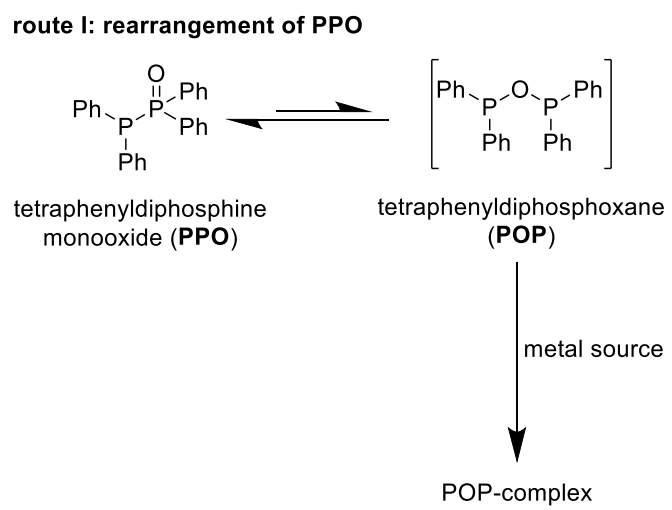

route II: template-synthese

$2 \underset{P_{\text {Ph }}}{\mathrm{Ph}} \underset{\text { water }}{\stackrel{\text { metal source }}{\longrightarrow}}$ POP-complex + 2 LG-H 
We performed no formal mechanistic studies regarding the degradation pathway from a $\mathrm{Cu}(\mathrm{I})-\mathrm{POQ}$ to $\mathrm{Cu}(\mathrm{I})-\mathrm{POP}$ species. However, from our results and similar reactions from the literature, we propose a mechanism for the reaction. While there is so far no concise analysis of a broad range of POP complexes in one single publication, the synthetic pathways proposed so far can be classified by either one of two groups (Scheme 1). Route I would be the thermal isomerization of PPO in the presence of a metal precursors, as described by Wong and co-workers. ${ }^{44}$ More common is route II, where a phosphine precursor with a leaving group is employed. In our case, $L^{-}$is the deprotonated form of 8-hydroxyquinoline, while Coetzee et al. used carboxylates as a leaving group and $\mathrm{Rh}$ as a metal centre. ${ }^{46}$ Zeiher and co-workers used sulfonates in combination with $\mathrm{Cr}$, Mo and $\mathrm{W},{ }^{47}$ while Renz and coworkers used 3-hydroxypyridine and Ag..$^{88}$ Older works describe the use of chloro-diphenylphosphine with chloride as a leaving group for precursors. 49,50

Scheme 2 contains our proposal for a degradation mechanism according to route II. We speculate that the first, rate-determining step (i) is the cleavage of the $\mathrm{Cu}-\mathrm{N}$ bond. From the molecular structures of $\mathbf{1}-\mathbf{B r}$ and $\mathbf{1 - I}$, it is evident that the bond between $\mathrm{Cu}$ and the quinoline- $\mathrm{N}$ is not weakened. After a 16-valence electron-species has been formed, water may coordinate (ii) and transfer a proton to the quinolate, which allows for the cleavage of the O-P bond. This step (iii) yields a $\mathrm{Cu}(\mathrm{I})(\mathrm{OH}) \mathrm{PPh}_{2}$ species, which can react with an additional equivalent of POQ to form POP.

Scheme 2: Proposed mechanism for the degradation of $\mathrm{Cu}(\mathrm{I})-\mathrm{POQ}$ complexes.

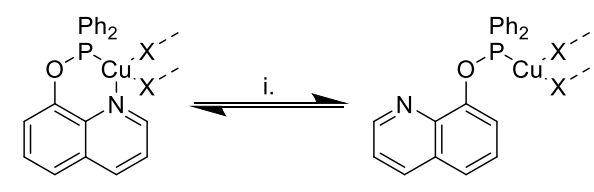

cleavage of the $\mathrm{Cu}-\mathrm{N}$-bond

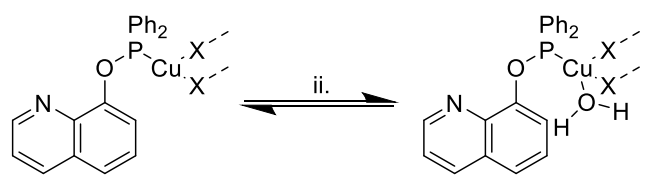

coordination of water

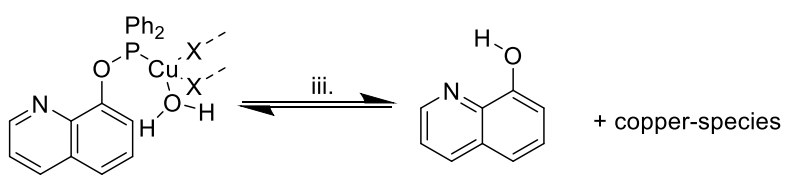

formation of hydroxyquinoline

$X=$ halide

pseudohalide

\section{CONCLUSION}

In this study, we investigated a new approach to create chelated copper compounds by covalent connection of two monodentate ligands, which yielded four copper(I) complexes. As expected, we obtained orange-to-red emission. However, the materials seemed to be prone to degradation in the presence of water. We formulated a hypothesis for the degradation mechanism based on several distorted bonds identified by analysis of single crystal X-ray diffraction and chemical analysis of the degraded solution.

From a material-developers point-of-view, the degradation reaction found in the POQ compounds needs to be suppressed in a future development step. So far, only limited knowledge and hypotheses exist regarding the degradation of $\mathrm{Cu}(\mathrm{I})$ OLED emitters. We believe that the finding that ligands that contain potential leaving groups may lead to destruction of the emissive compounds might be a general one. Also, the hypotheses that strained or compressed bonds need to be avoided needs to be further investigated.

\section{ASSOCIATED CONTENT}

\section{Supporting Information}

Synthetic procedures, information regarding the preparation of the single crystal samples as well as spectroscopic details. This material is available free of charge via the Internet at http://pubs.acs.org.

CCDC-1441665 (1-Br), CCDC-1441666 (1-I), CCDC-1441671 (POP-Br-1), CCDC-1441677 (POP-Br-2) and CCDC-1441679 (POP-SCN) contain the supplementary crystallographic data for this paper. These data can be obtained free of charge from The Cambridge Crystallographic Data Centre via www.ccdc.cam.ac.uk/data request/cif.

\section{AUTHOR INFORMATION}

\section{Corresponding Author}

braese@kit.edu,volz@cynora.com

Notes

The authors declare no competing financial interests.

\section{ACKNOWLEDGMENT}

Financial support from the Deutsche Forschungsgemeinschaft (DFG) via support for the transregional collaborative research center SFB/TRR 88 "3MET", the BioInterfaces program, and the Deutsche Telekom Stiftung are acknowledged.

\section{REFERENCES}


Volz, D.; Wallesch, M.; Fléchon, C.; Danz, M.; Verma, A.; Navarro, J. M.; Zink, D. M.; Bräse, S.; Baumann, T. Green Chem. 2015, 17 (4), 1988.

Xiao, P.; Zhang, J.; Campolo, D.; Dumur, F.; Gigmes, D.; Fouassier, J. P.; Lalevée, J. J. Polym. Sci. Part A Polym. Chem. 2015, n/a.

(4) Zhang, P.; Wang, M.; Yang, Y.; Yao, T.; Sun, L. Angew. Chem. Int. Ed. Engl. 2014, 1.

Wang, Y.-M.; Teng, F.; Hou, Y.-B.; Xu, Z.; Wang, Y.-S.; Fu, W.-F. Appl. Phys. Lett. 2005, 87 (23), 233512.

Volz, D.; Chen, Y.; Wallesch, M.; Liu, R.; Fléchon, C.; Zink, D. M.; Friedrichs, J.; Flügge, H.; Steininger, R.; Göttlicher, J.; Heske, C.; Weinhardt, L.; Bräse, S.; So, F.; Baumann, T. Adv. Mater. 2015, 27 (15), 2538.

(7) Leitl, M. J.; Küchle, F.-R. R.; Mayer, H. A.; Wesemann, L.; Yersin, H. J. Phys. Chem. A 2013, 117 (I), 11823.

Czerwieniec, R.; Yu, J.; Yersin, H. Inorg. Chem. 2011, 50 (17), 8293.

(9) Araki, H.; Tsuge, K.; Sasaki, Y.; Ishizaka, S.; Kitamura, N.; Ligands, N.; Br, N. X. Inorg. Chem. 2005, 44 (26), 9667.

(10) Araki, H.; Tsuge, K.; Sasaki, Y.; Ishizaka, S.; Kitamura, N. Inorg. Chem. 2007, 46 (24), 10032.

(11) Wallesch, M.; Volz, D.; Zink, D. M.; Schepers, U.; Nieger, M.; Baumann, T.; Bräse, S. Chem. - A Eur. J. 2014, 20 (22), 6578 .

(12) Volz, D.; Bergmann, L.; Zink, D. M.; Baumann, T.; Bräse, S. In SPIE Newsroom; 2013

(13) Engelhardt, L.; Healy, P.; Kildea, J.; White, A. Aust. J. Chem. 1989, 42 (6), 945.

(14) Healy, P. C.; Whittaker, A. K.; Kildea, J. D.; Skelton, B. W.; White, A. H. Aust. J. Chem. 1991, 44, 729.

(15) Cingolani, A.; Martini, D.; Pettinari, C.; Skelton, B. W.; White, A. H. Inorganica Chim. Acta 2006, 359 (7), 2183.

(16) Bowmaker, G. A.; Dyason, J. C.; Healy, P. C.; Engelhardt, L M.; Pakawatchai, C.; White, A. H. Dalt. Trans. 1987, No. 5, 1089.

(17) Lastra, E.; Gamasa, M. P.; Gimeno, J.; Lanfranchi, M.; Tiripicchio, A. Dalt. Trans. 1989, No. 8, 1499.

(18) Effendy; Di Nicola, C.; Fianchini, M.; Pettinari, C.; Skelton, B. W.; Somers, N.; White, A. H. Inorganica Chim. Acta 2005, 358 (3), 763 .

(19) Hirtenlehner, C.; Monkowius, U. Inorg. Chem. Commun. 2012, 15, 109 .

(20) Tsuge, K. Chem. Lett. 2013, 42 (3), 204.
(21) Volz, D.; Zink, D. M.; Bocksrocker, T.; Friedrichs, J.; Nieger, M.; Baumann, T.; Lemmer, U.; Bräse, S. Chem. Mater. 2o13, 25 (17), 3414.

(22) Zink, D. M.; Volz, D.; Baumann, T.; Mydlak, M.; Flügge, H.; Friedrichs, J.; Nieger, M.; Bräse, S. Chem. Mater. 2013, 25 (22), 4471.

(23) Volz, D.; Nieger, M.; Friedrichs, J.; Baumann, T.; Bräse, S. Inorg. Chem. Commun. 2013, 37, 106.

(24) Zink, D. M.; Bächle, M.; Baumann, T.; Nieger, M.; Kühn, M.; Wang, C.; Klopper, W.; Monkowius, U.; Hofbeck, T.; Yersin, H.; Bräse, S. Inorg. Chem. 2013, 52 (5), 2292.

(25) Zink, D. M.; Baumann, T.; Friedrichs, J.; Nieger, M.; Bräse, S. Inorg. Chem. 2013, 52 (23), 13509.

(26) Kobayashi, A.; Komatsu, K.; Ohara, H.; Kamada, W.; Chishina, Y.; Tsuge, K.; Chang, H. C.; Kato, M. Inorg. Chem. 2013, 52 (22), 13188.

(27) Wallesch, M.; Volz, D.; Fléchon, C.; Zink, D. M.; Bräse, S.; Baumann, T. In Proceedings of SPIE; So, F., Adachi, C., Eds.; 2014; p 918309.

(28) Volz, D.; Cheng, Y.; Liu, R.; Wallesch, M.; Zink, D.; Göttlicher, J.; Steininger, R.; Flügge, H.; Fléchon, C.; Navarro, J.; Bräse, S.; So, F.; Baumann, T. Adv. Mater. 2015.

(29) Wyckoff, R. W. G.; Posnjak, E. J. Am. Chem. Soc. 1922, 44 (1), 30 .

(30) Healy, P.; Kildea, J.; Skelton, B.; White, A. Aust. J. Chem. 1989, $42(1), 93$.

(31) Dyason, J. C.; Healy, P. C.; Engelhardt, L. M.; Pakawatchai, C.; Patrick, V. A.; Raston, C. L.; White, A. H. J. Chem. Soc. Dalt. Trans. 1985, No. $4,831$.

(32) Engelhardt, L.; Healy, P.; Kildea, J.; White, A. Aust. J. Chem. 1989, $42(6), 895$.

(33) Healy, P. C.; Pakawatchai, C.; White, A. H. J. Chem. Soc. Dalt. Trans. 1983, No. 9, 1917.

(34) Barron, P. F.; Dyason, J. C.; Engelhardt, L. M.; Healy, P. C.; White, A. H. Inorg. Chem. 1984, 23 (23), 3766.

(35) Dyason, J. C.; Engelhardt, L. M.; Healy, P. C.; Pakawatchai, C.; White, A. H. Inorg. Chem. 1985, 24 (12), 1950.

Healy, P.; Skelton, B.; Waters, A.; White, A. Aust. J. Chem. 1991, 44 (8), 1049.

Churchill, M. R.; Kalra, K. L. Inorg. Chem. 1974, 13 (5), 1065.

(38) Krautscheid, H.; Emig, N.; Klaassen, N.; Seringer, P. J. Chem. Soc. Dalt. Trans. 1998, No. 18, 3071.

(39) Pettinari, C.; di Nicola, C.; Marchetti, F.; Pettinari, R.; Skelton, B. W.; Somers, N.; White, A. H.; Robinson, W. T.; Chierotti, M. R.; Gobetto, R.; Nervi, C. Eur. J. Inorg. Chem. 2008, 2008 (12), 1974. 
(40) Langer, J.; Görls, H.; Gillies, G.; Walther, D. Zeitschrift für Anorg. und Allg. Chemie 2005, 631 (13-14), 2719.

(41) Benito-Garagorri, D.; Lackner-Warton, W.; StandfestHauser, C. M.; Mereiter, K.; Kirchner, K. Inorganica Chim. Acta 2010, 363 (14), 3674.

(42) Wong, E. H.; Bradley, F. C.; Prasad, L.; Gabe, E. J. J. Organomet. Chem. 1984, 263 (2), 167.

(43) Bradley, F. C.; Wong, E. H.; Gabe, E. J.; Lee, F. L.; Lepage, Y. Polyhedron 1987, 6 (5), 1103.

(44) H. Wong, E.; Prasad, L.; J. Gabe, E.; C. Bradley, F. J. Organomet. Chem. 1982, 236 (3), 321.

(45) Naktode, K.; Kottalanka, R. K.; Adimulam, H.; Panda, T. K. J. Coord. Chem. 2014, 67 (18), 3042.

(46) Coetzee, J.; Eastham, G. R.; Slawin, A. M. Z.; ColeHamilton, D. J. Dalton Trans. 2014, 43 (9), 3479.

(47) Zeiher, C.; Mohyla, J.; Lorenz, I.-P.; Hiller, W. J. Organomet. Chem. 1985, 286 (2), 159.

(48) Renz, A.; Penney, M.; Feazell, R.; Klausmeyer, K. K. J. Chem. Crystallogr. 2012, 42 (11), 1129.

(49) Kraihanzel, C. S.; Bartish, C. M. J. Am. Chem. Soc. 1972, 94 (10), 3572 .

(50) Gray, G. M.; Kraihanzel, C. S. J. Organomet. Chem. 1982, 238 (2), 209 